\title{
Impactos ambientais oriundos da extração de calcário laminado em Santana do Cariri (CE)
}

A exploração do calcário laminado em Santana do Cariri (CE) é considerada umas das principais atividades econômicas do município, aliada à agricultura de subsistência e à mineração da gipsita. Esse recurso mineral, assim como outros, quando explorado de forma inadequada geram impactos de caráter ambiental e social. Nesse contexto, a presente pesquisa tem como objetivo realizar uma avaliação dos impactos ambientais ocasionados pela extração do calcário laminado em uma mina a céu aberto localizada no bairro Inhumas desse município. Trata-se de um estudo de abordagem qualitativa e descritiva, onde foram utilizados métodos como: pesquisa bibliográfica, pesquisa de campo e entrevistas semiestruturadas com representantes da mineração em estudo. Dentre os resultados obtidos, constatou-se que a exploração do calcário laminado está sendo realizada sem nenhum acompanhamento profissional especializado e com a utilização de equipamentos rudimentares, o que tem contribuído para elevação das perdas de materiais durante o processo de lavra e consequentemente tem aumentado a acumulação de rejeitos de calcários nos arredores da jazida. Além do excesso de rejeitos, nota-se a alteração da paisagem local, o assoreamento do Rio Cariús e a destruição irreversível de fósseis. Diante dessa problemática, faz-se necessária uma atuação imediata dos órgãos públicos no planejamento de medidas mitigatórias com a finalidade de diminuir os efeitos degradantes resultantes desta atividade de extração mineral.

\section{Environmental impacts from laminated limestone extraction in Santana do Cariri (CE)}

\begin{abstract}
The exploration of laminated limestone in Santana do Cariri (CE) is considered one of the main economic activities of the municipality, combined with subsistence agriculture and gypsum mining. This mineral resource, as well as others, when improperly exploited generates environmental and social impacts. In this context, this research aims to carry out an assessment of the environmental impacts caused by the extraction of rolled limestone in an open pit mine located in the Inhumas neighborhood of this municipality. This is a qualitative and descriptive study, using methods such as bibliographic research, field research and semi-structured interviews with representatives of the mining under study. Among the results obtained, it was found that the exploration of laminated limestone is being carried out without any specialized professional monitoring and the use of rudimentary equipment, which has contributed to increase material losses during the mining process and consequently has increased the accumulation of limestone tailings around the deposit. In addition to the excess tailings, there is the alteration of the local landscape, the silting of the Rio Cariús and the irreversible destruction of fossils. Given this problem, immediate action by public agencies is necessary in the planning of mitigating measures in order to reduce the degrading effects resulting from this activity of mineral extraction.
\end{abstract}

Keywords: Laminated limestone; Environmental impacts; Sustainability.

Topic: Desenvolvimento, Sustentabilidade e Meio Ambiente

Reviewed anonymously in the process of blind peer
Received: 04/07/2018

Approved: $13 / 10 / 2018$
Esdras Alex Freire de Oliveira (iD)

Universidade Regional do Cariri, Brasil

http://lattes.cnpq.br/4693470747465264

http://orcid.org/0000-0001-6246-3009

esdras-alex@hotmail.com

Sheilla da Silva Melo Figueirêdo (D)

Universidade Federal do Cariri, Brasil

http://lattes.cnpq.br/5511200899904144

http://orcid.org/0000-0002-7397-4207

sheillamel@hotmail.com

Jamily Freire Gonçalves (iD

Universidade Regional do Cariri, Brasil

http://lattes.cnpq.br/6842629450911164

http://orcid.org/0000-0003-0537-213X

jamilyfreire@gmail.com

\author{
Thatiany Alencar Batista \\ Universidade Federal Fluminense, Brasil \\ http://lattes.cnpq.br/9607255646013062 \\ thatianypaleo2011@gmail.com

\section{Ivan Cézar Alencar Homem} \\ Universidade Federal Fluminense, Brasi \\ http://lattes.cnpq.br/9607255646013062 \\ ivancezar93@hotmail.com \\ Thays Lorranny da Silva Januário \\ Universidade Federal Fluminense, Brasil \\ http://lattes.cnpq.br/9607255646013062 \\ eng.thays@hotmail.com
}

Referencing this:

OLIVEIRA, E. A. F.; FIGUEIRÊDO, S. S. M.; GONÇALVES, J. F.; BATISTA, T. A.; HOMEM, I. C. A.; JANUÁRIO, T. L. S.. Impactos ambientais oriundos da extração de calcário laminado em Santana do Cariri (CE). Natural Resources, v.8, n.2, p.21-30, 2018. DOI:

http://doi.org/10.6008/CBPC2237-9290.2018.002.0003 


\section{INTRODUÇÃO}

A mineração é considerada, internacionalmente, uma atividade extrativista de grande potencial socioeconômico, em razão dos produtos minerários serem uma fonte promissora de riquezas e trabalho para diversas famílias. Porém, a ocupação territorial pela humanidade na busca incessante pela exploração de minerais no subsolo, tem ocasionado desastres ambientais em decorrência das frequentes necessidades de escavações e da geração excessiva de rejeitos. Segundo Durães (2017), a atividade de extração mineral é extremamente impactante para o ambiente, pois pode acarretar na supressão da vegetação e impossibilitar a sua regeneração, além de provocar a contaminação do solo favorece a formação de processos erosivos, a instabilidade de taludes e a destruição dos recursos hídricos.

Conforme Moura et al. (2014), os calcários são rochas sedimentares constituídas por carbonato de cálcio, magnésio e outros minerais em pequenas quantidades (ferro, alumínio, silicatos e argilas), originados de materiais precipitado por agentes químicos e orgânicos, no qual são utilizados na fabricação de blocos para a indústria da construção, como material para agregados, cimento, cal, e até rochas ornamentais. 0 calcário apresenta uma grande variedade de usos, desde matéria prima para a construção civil, material para agregados, matéria prima para a fabricação de cal, fonte de ligante hidráulico (cal) na fabricação de cimento, e até como rocha ornamental (SANTOS, 2015).

De acordo com dados do DNPM (2016), no ano de 2014, a reserva mineral de calcário foi quantificada no Ceará em aproximadamente 6,5 bilhões de toneladas em estado bruto, com área lavrável mensurada em torno de 4,8 bilhões de toneladas e produção de cerca 2,7 milhões de toneladas/ano. No município de Santana do Cariri, a extração de calcário laminado é tida como uma das principais atividades econômicas fornecedora de renda para diversas famílias, aliada a agricultura e a mineração de gipsita. Esse município está localizado na região do Cariri no sul do Estado do Ceará, no qual faz parte da Formação Crato do Grupo Santana inserida na Chapada do Araripe.

Segundo Caselli et al. (2015), a exploração do calcário laminado na região do Cariri é voltada para o setor da construção civil e tem contribuído significativamente na geração de empregos (1500 empregos diretos e 4000 indiretos), sendo que a cidade de Nova Olinda e Santana do Cariri são responsáveis por cerca de $15 \%$ da produção de agregados de calcário para o setor da construção civil.

A Formação Crato representa um sistema aptiano carbonático lacustre/fluvial, com um ambiente de águas rasas e calmas, além de ser um ambiente hipersalino e anóxico, o que auxilia na preservação de diversos organismos, representados assim um dos mais importantes sítios paleontológicos do mundo (BÁEZ et al., 2009; BARDOLA, 2015; NEUMANN et al., 2002). Em relação às unidades de formação geológica da bacia sedimentar do Araripe, a Formação Santana é de maior interesse para a mineração por ser essencialmente constituída por minerais como: calcário laminado e gipsita, além de compor um grande sítio paleontológicos.

A mineração tornou-se, ao longo dos anos, uma atividade indispensável para a vida humana, perante o amplo fornecimento de matéria-prima oriunda da extração e beneficiamento das mais diversas substâncias minerais existentes no planeta. Diante disso, manter um equilíbrio entre a atual forma de produção capitalista e o desenvolvimento sustentável, tem sido o grande desafio da humanidade nos últimos séculos. 
Conforme Bezerra (2015) o conhecimento sobre a importância dos recursos minerais para a vida do homem moderno é um fator indispensável para o surgimento de medidas mitigatórias, que possa reduzir o desperdício de bens minerais e, assim, minimizar os problemas ambientais ocasionados pela lavra e consequentemente prevenir a escassez das minas.

Com base nesse contexto, objetivou-se desenvolver nessa pesquisa uma avaliação dos impactos ambientais acarretado pela extração do calcário laminado no município de Santana do Cariri/Ceará. Sendo assim, esse estudo pretende oferecer subsídios que possa possibilitar a identificação dos problemas ambientais provocados pela atividade extrativista do calcário e de forma análoga contribuir na minimização desses impactos, que a três décadas tem afetado de forma negativa os recursos naturais daquela localidade. Cabe ressaltar que a presente pesquisa será desenvolvida em uma mineração de calcário localizada no antigo distrito de Inhumas, que recentemente passou a ser considerado bairro na cidade de Santana do Cariri.

\section{REVISÃO TEÓRICA}

O atual quadro de degradação das condições ambientais possui raiz na exploração e acumulação desenfreada dos recursos naturais (OLIVEIRA FILHO, 2013). De acordo com Oliveira Filho (2013), detectar os fatores que impactam negativamente o meio ambiente e identificar suas atuais consequências será imensamente importante para implantar políticas públicas e mecanismos que previnam ou até minimize esses impactos ambientais futuramente.

Compreende-se por impactos ambientais as alterações ocorridas no meio ambiente ou na qualidade de seus componentes pela ação humana, promovendo, assim, o desequilíbrio ecológico. A resolução no 001 do Conselho Nacional do Meio Ambiente - CONAMA conceitua impactos ambientais como qualquer alteração das propriedades físicas, químicas e biológicas do ambiente, provocada por qualquer forma de energia ou matéria resultante da ação humana, que de maneira direta ou indireta possa prejudicar: a saúde, a segurança e o bem-estar humano; as atividades sociais e econômicas; a biota; as condições estéticas e sanitárias do meio ambiente e a qualidade dos recursos naturais.

A resolução CONAMA no 001 pressupõe que os empreendedores antes de iniciarem suas atividades de extração mineral devem providenciar a elaboração do Estudo de Impactos Ambientais (EIA), juntamente com o respectivo Relatório de Impactos Ambientais (RIMA), sendo passível de aprovação pelo órgão estadual competente. Ainda conforme essa resolução, na elaboração do (EIA) e do (RIMA) deve contemplar todas as alternativas tecnológicas e de localização confrontando-as com a hipótese de não execução do projeto, identificar e avaliar sistematicamente os impactos ambientais gerados nas fases de implantação e operação da atividade, definir a área direta e indiretamente afetadas pelos impactos e considerar os planos e programas de governo com jurisdição sobre a área onde será implementada a atividade impactante.

Para Sánchez (2013) a elaboração do EIA somente é obrigatório quando for constatado que a atividade extrativista possa provocar impactos significativos no ambiente, sendo que na inexistência de tais impactos, torna-se necessária a elaboração de outros tipos de estudos em carácter mais simplificado, como requisitos técnicos para obtenção do direito mineral. 
Os primeiros indícios sobre licenciamento ambiental no Brasil surgiram com a aprovação da Política Nacional do Meio Ambiente - PNMA no ano de 1981 (Lei 6.938/81). Segundo Bizawu et al. (2017) foi com o Decreto 99.274/1990 que o processo de licenciamento ambiental passou a ser vinculado ao AIA (Avaliação de Impactos Ambientais), sendo que esse decreto concedeu ao CONAMA a competência para fixar os procedimentos necessários na concessão de licenças.

Conforme Bizawu et al. (2017), quando se tratar de exploração de recursos minerais o processo de licenciamento deve ser iniciado junto ao Departamento Nacional de Produção Mineral - DNPM. De acordo com a resolução no 237/1997 do CONAMA, serão expedidos os seguintes tipos de licenças: Licença Prévia (LP) concedida na fase preliminar do planejamento da atividade, Licença de Instalação (LI) que autoriza a instalação do empreendimento e a Licença de Operação (LO) que autoriza o início das atividades.

\section{Características geológicas do município de Santana do Cariri}

O município de Santana do Cariri está localizado no sul do Estado cearense, no qual faz parte da região do Cariri. De acordo com o censo demográfico elaborado pelo IBGE (2010), o território santanense possui uma população equivalente a 17.170 habitantes. Segundo o IPECE (2016), o município de Santana do Cariri possui coordenadas geográficas de 70 11' 18'" (Latitude) e 39o 44' 13’ (Longitude) com uma área absoluta de $855,6 \mathrm{~km}^{2}$, estando a uma distância de 406 quilômetros da capital em linha reta. Ainda segundo dados do IPECE (2016), esse município possui clima semiárido com precipitação média em cerca de 972,8mm anuais (período chuvoso entre os meses de janeiro a maio), com predominância do relevo da Chapada do Araripe. A Chapada do Araripe é um planalto localizado dentro do domínio da Caatinga no nordeste brasileiro, mais precisamente entre os estados do Ceará, Pernambuco e Piauí (NOVAES et al., 2014).

De acordo com CPRM (1998), o quadro geológico do município de Santana do Cariri apresenta rochas do embasamento cristalino pré-cambriano, representado por gnaisses e migmatitos variados, quartzitos e metacalcários de composição granítica, com relevo tabular no sentido sul composta pela Chapada do Araripe e ao norte compondo o relevo da Depressão Sertaneja. Conforme o CPRM (1998), os solos identificados no município são do tipo latossolos, litólicos, terra roxa estruturada e vertissolos, sendo cobertos por diversas espécies de vegetação como: cerrado, mata seca, mata úmida, caatinga arbórea e carrasco.

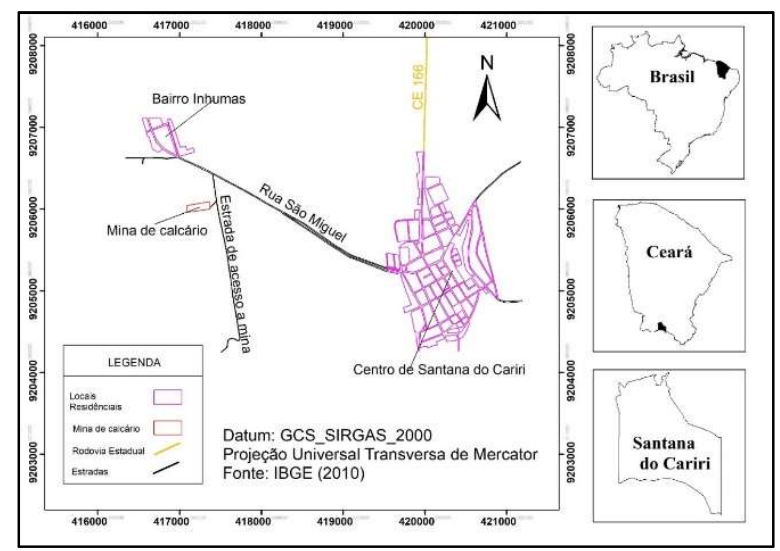

Figura 1: Localização da mina de calcário em Santana do Cariri. 


\section{METODOLOGIA}

O método utilizado nessa pesquisa constitui-se de uma abordagem qualitativa e descritiva. Para tanto, foram realizadas pesquisas na literatura pertinente objetivando obter maior familiaridade sobre questões referentes a avaliação de impactos ambientais e ao licenciamento ambiental presentes em artigos científicos e na legislação ambiental nacional. Conforme Creswell (2010) o conceito de pesquisa qualitativa pode ser entendido como:

[...] começa com pressupostos e o uso de estruturas interpretativas/teóricas que informam o estudo dos problemas da pesquisa, abordando os significados que os indivíduos ou grupos atribuem a um problema social ou humano. Para estudar esse problema, os pesquisadores qualitativos usam uma abordagem qualitativa da investigação, a coleta de dados em um contexto natural sensível às pessoas e aos lugares em estudo e análise dos dados que é tanto indutiva quanto dedutiva e estabelece padrões ou temas. $O$ relatório final ou a apresentação incluem as vozes dos participantes, a reflexão do pesquisador, uma descrição complexa e interpretação para a literatura ou um chamado à mudança.

$\mathrm{Na}$ coleta de dados, foram utilizados procedimentos relacionados a pesquisa de campo como: observação in loco da extração de calcário, registros de imagens e apuração dos tipos de maquinários utilizados na atividade de lavra. Também foram observados a existência de recursos hídricos próximo ao local onde é realizado a extração de calcário e, posteriormente, utilizado software como Google Earth e ArcMap, como ferramentas para auxiliar na caracterização da área pesquisada.

\section{RESULTADOS E DISCUSSÃO}

A pesquisa foi desenvolvida em uma extração de calcário a céu aberto situada no antigo distrito Inhumas da cidade de Santana do Cariri, que recentemente passou a ser considerado bairro. O local onde é realizado a atividade extrativista está a uma distância de aproximadamente 700 metros das residências familiares desse bairro e a 2 quilômetros do centro da cidade.

A jazida em estudo possui uma área total em torno de $6.610 \mathrm{~m}^{2}$, no qual somente uma pequena parte equivalente a $2.669 \mathrm{~m}^{2}$ está sendo utilizada para extração, pois o restante da mina encontra-se com as atividades paralisadas devido ao esgotamento do minério próximo a superfície do solo. As escavações são realizadas de acordo com a qualidade e quantidade da rocha encontrada no sobsolo, sendo caracterizado como um processo de exploração rudimentar efetuado de forma empírica. Cabe ressaltar que na mineração em estudo são produzidos somente agregados para construção civil.

Durante as visitas realizadas no local da mina ficou constatado que a atividade extrativista é realizada por uma família que residente no bairro Inhumas da cidade de Santana do Cariri, todavia os mesmos não possuem registro empresarial e licença para efetuar a exploração de tal jazida. Porém, as pessoas responsáveis pela exploração do calcário nesses locais informaram que já solicitaram o registro empresarial para regularização da atividade.

Foram realizadas consultas no site do DNPM e verificado no mapa do Ceará a lista de todas as áreas requisitadas para mineração, porém no local em estudo encontra-se em processo de disponibilidade, ou seja, essas áreas estão disponíveis para pesquisa e lavra sobre critério licitatório estabelecido pelo DNPM. Na figura 2 pode-se verificar o local em estudo utilizado na exploração de calcário. 


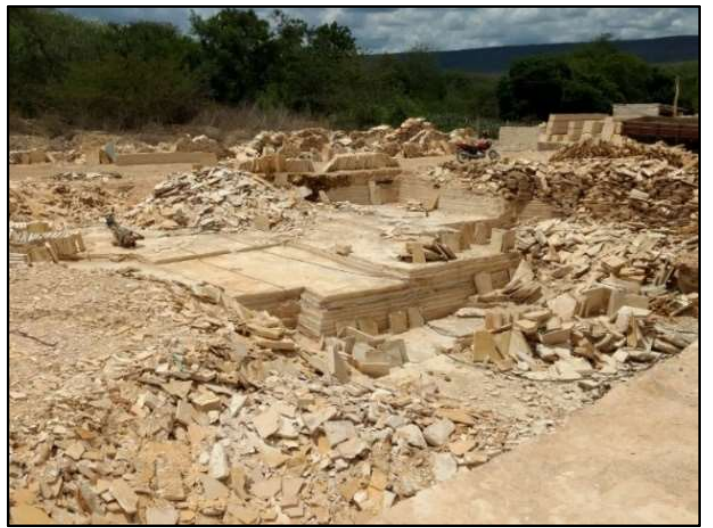

Figura 2: Local utilizado para mineração de calcário laminado.

Convém observar que a pedreira onde é executada as escavações para beneficiamento das rochas de calcário fica próxima a locais residenciais, ao Rio Cariús (rio intermitente que nasce na encosta da chapada do Araripe) e a um córrego que se originou pela ação das chuvas, que se estende até esse rio. O processo de lavra é iniciado com a análise do potencial calcário existente no terreno, sendo que essa avaliação preliminar é efetuada por um indivíduo detentor de conhecimento empírico, ou seja, com base na experiência adquirida ao longo dos anos desenvolvendo essa atividade, o que certamente implica em erro, dada a falta de um acompanhamento especializado.

Segundo Bezerra (2015) os métodos de lavra utilizado no beneficiamento do calcário laminado nessa região são praticamente inadequados, em razão do uso de tecnologias rudimentares e da ausência de acompanhamento técnico por um profissional especializado. Antigamente, a extração de calcário nesse município era desenvolvida apenas com a utilização de equipamentos manuais como: picareta, pás e alavancas. Com o passar dos anos os mineradores passaram a usar máquinas de cortes moveis, tratores e explosivos no que resultou no aumento das áreas exploradas, na melhor qualidade dos produtos e consequentemente na redução das perdas durante o processo de beneficiamento. Silva et al. (2007), versando sobre a lavra, afirma que:

A lavra é desenvolvida, na sua grande maioria, com métodos rudimentares. Contudo em algumas pedreiras essa lavra é conduzida de forma semimecanizada, através da utilização de máquinas de corte móveis, acionadas por eletricidade, com disco diamantado. Após esta etapa, as placas são selecionadas manualmente e transportadas para o beneficiamento nas serrarias onde é esquadrejada em dimensões compatíveis a sua aplicação. Essa atividade gera, nas frentes de lavra, uma grande quantidade de rejeitos prejudiciais ao meio ambiente, tanto por formar entulhos, impossibilitando o acesso ao pátio de movimentação, bem como gerando um impacto visual desagradável.

Logo após a análise da área, segue-se para a etapa de limpeza da jazida, que consiste na remoção da camada superficial do solo e da vegetação e em seguida todo o rejeito é retirado e acumulado nos arredores da mina. Posteriormente, é efetuado a extração da rocha utilizando uma ferramenta denominada policorte, sendo que esse equipamento consiste em um dispositivo portátil composto por um motor elétrico, que aciona uma lâmina circular de material metálico posicionada verticalmente.

Essa ferramenta executa o esquadrejamento da rocha sedimentar em diferentes tamanhos, porém as chapas fabricadas não ficam com suas dimensões totalmente perfeitas. As chapas de calcário fabricadas 
na jazida em estudo são esquadrejadas em tamanhos variados e conforme a demanda de mercado, sendo que os principais tamanhos fabricados são: $50 \times 50 \mathrm{~m}^{2}, 40 \times 40 \mathrm{~m}^{2}$ e $30 \times 30 \mathrm{~m}^{2}$.

Em seguida, as pedras de calcário semiacabadas são transportadas em carrinhos de mão até as serrarias, onde passaram por um processo de ajustes nas suas dimensões. Essas serrarias são constituídas basicamente por uma mesa de metal equipada com uma serra elétrica e um fluxo de água. 0 objetivo da utilização de água durante esse processo é para evitar a formação e disseminação da poeira mineral (estilhaços de rocha com diâmetros bem pequenos) liberada durante a serragem das chapas de calcário.

Conforme ressaltado por Mendonça (2008), o material particulado liberado durante o beneficiamento das placas de calcário, que são constituídos por fragmentos extremamente pequenos (pulverulento), contribui significativamente na contaminação dos recursos hídricos adjacentes a mina, através do aumento das concentrações de cálcio na composição da água, deixando-a com uma dureza elevada.

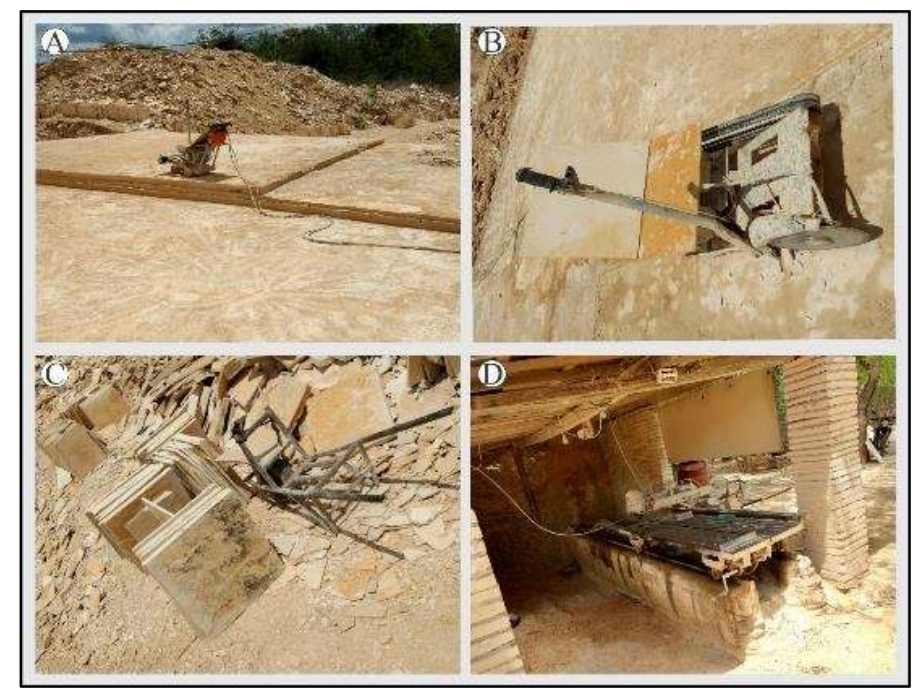

Figura 3: A) Limpeza e preparação da mina; B) Ferramenta de corte/Policorte; C) Transportes das chapas realizada em carros de mão; D) Mesa de serragem.

Na figura 3, pode-se observar o processo rudimentar utilizado na extração de calcário em Santana do Cariri, o que certamente tem contribuído de forma significativa para o aumento na quantidade de rejeitos originados durante o processo de lavra. A mineração é um fator importante para o desenvolvimento local, no entanto, os processos da mineração e beneficiamento gera uma grande quantidade de rejeito, que são responsáveis por danos ao meio ambiente, ainda não devidamente dimensionados (BEZERRA, 2015).

A comercialização e beneficiamento das chapas de calcário nesse município compõem-se essencialmente por um conjunto de microempresas ou pelas próprias famílias detentoras dos terrenos, que conduzem a atividade em condições precárias com ausência de EPI (Equipamento de Proteção Individual) e EPC (Equipamento de Proteção Coletiva), sem nenhum cumprimento de normas trabalhistas, o que se caracteriza, sob este ponto de vista, como uma atividade realizada de forma irregular.

Durante as visitas realizadas na área de exploração da mina, pôde-se constatar a diversidade de impactos ambientais que essa atividade extrativista tem ocasionado ao ecossistema local. Dentre esses impactos, pode-se citar o desmatamento da flora regional originados pela abertura das estradas que dar 
acesso as jazidas e da retirada da camada de solo e da vegetação que cobre essas áreas, para que após todo esse processo seja iniciado a extração da rocha. Além disso, a geração de rejeitos em decorrência da lavra tem favorecido o assoreamento do rio Cariús que passa próximo da área da mineração de calcário. Na figura abaixo pode ser observado o rejeito decorrente da lavra de calcário.

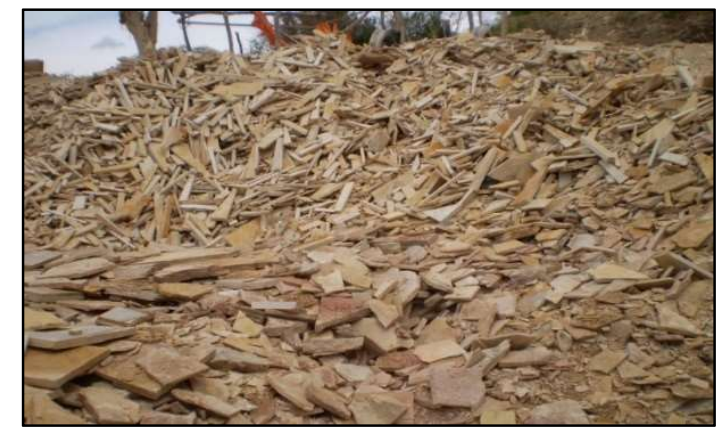

Figura 4: Rejeitos do calcário laminado.

A paisagem da região é largamente afetada, principalmente pela quantidade de rejeitos que são acumulados nas proximidades das minas, além das enormes crateras resultantes das escavações extensivas, conforme verificado na figura 4. No entanto, toda a cadeia produtiva compreendendo as etapas de lavra e beneficiamento, acarreta uma perda total em torno de 70\% (SILVA et al., 2007). Na região, tem-se utilizado o rejeito do calcário na construção de estradas e fornecida como matéria-prima para indústria de fabricação de cimento, porém essas medidas mitigatórias são consideradas quase irrelevantes diante da quantidade de materiais que são empilhados nas imediações da mina.

Evidentemente que a extração das rochas calcárias tem contribuído para a migração da fauna local. Entretanto, esse problema se intensificou devido a propagação do barulho provenientes da detonação de explosivos no local, da utilização de máquinas elétricas durante o desenvolvimento dessa atividade e do trânsito de veículos automotores. Pode-se notar também, dentre as questões citadas, a perda intensa e irreversível dos fósseis existentes naquela região.

Outro fator constatado durante as visitas realizadas nos locais de exploração do calcário são os problemas relacionados as crateras que estão inabilitadas ou até abandonadas devido ao esgotamento da jazida ou pela baixa qualidade da rocha, o que acaba tornando-se no período chuvoso enormes reservatórios de águas paradas. Essa acumulação de água nesses reservatórios pode contribuir na proliferação de diversos insetos causadores de doenças, além de possibilitar e favorecer a ocorrência de acidentes envolvendo adolescentes e crianças que eventualmente venham a transitar por essas áreas.

A poluição sonora tem-se configurado como um outro problema sendo de caráter social, em decorrência do intenso barulho associado a detonação de explosivos nos locais da jazida e ao ruído que advém da operação de máquinas elétricas e do trânsito de tratores e caminhões utilizados no transporte das chapas que são fabricadas. Esse excesso de ruído provenientes da atividade de extração mineral pode, de certa forma, comprometer a saúde física/mental da população que residem nas proximidades da mina.

O conceito de preservação ambiental não se restringe somente à conservação da biodiversidade e dos recursos naturais, mas está diretamente ligada a qualidade de vida do homem e também da sua própria 
existência. A legislação brasileira em relação ao contexto ambiental é bastante ampla, pois aborda aspectos ligados ao tratamento adequado de resíduos sólidos e líquidos, a questão de controle do desmatamento e da emissão de gases tóxicos. Porém, os diversos problemas ambientais que assolam os recursos naturais não resultam especificamente da ausência de normas e leis, mas da ineficiência das ações voltadas a educação ambiental, da precariedade e corruptibilidade dos meios de fiscalização existentes.

De acordo com os aspectos presentes nas Normas Regulamentadoras de Mineração - NRM, aprovada pela portaria no 237 em outubro de 2001 (DNPM, 2001), no planejamento e desenvolvimento de minas a céu aberto devem ser considerados os aspectos referentes a geologia, topografia e condições ambientais, além disto faz-se necessária que toda área explorada esteja representada através de mapas e a disposição de todos, com as seguintes informações: amarração topográfica da localização de toda área em lavra e dos sistemas de disposição de estocagem de solo vegetal, estéril, produtos, rejeitos sólidos e líquidos.

Essa norma ainda estabelece que, no projeto da mina, devem ser adotadas medidas preventivas contra inundações e ações que visem tanto a economicidade do empreendimento, como possa proporcionar facilidade no desenvolvimento das atividades e garanta a segurança operacional da equipe de trabalho, o controle ambiental e ofereça condições para reabilitação da área degradada. As vias de trânsito que dão acesso as jazidas devem ser sinalizadas com largura mínima duas vezes maior que a largura do maior veículo utilizado, no caso de pista simples, e três vezes maior para pistas duplas. Em relação a vias de trânsito não pavimentadas, as mesmas devem ser umidificadas de forma a minimizar a geração e propagação de poeiras.

Segundo a NRM-19 (Disposição de Estéril, Rejeitos e Produtos) (DNPM, 2001), o tratamento atribuído aos estéreis, rejeitos e produtos devem ser planejados conforme a composição mineralógica da jazida, sendo que a construção de depósitos desses materiais necessita ser precedida de estudos geotécnicos, hidrológicos e hidrogeológicos. Os rejeitos necessitam ser acondicionados em depósitos construídos com dispositivos de drenagem interna de forma que não permitam a saturação do maciço, sendo que todo processo de exploração mineral deve dispor de um acompanhamento técnico especializado por profissional habilitado, além de possuir as devidas licenças ambientais previstas na legislação nacional.

\section{CONSIDERAÇÕES FINAIS}

Em Santana do Cariri, a mineração do calcário sedimentar tem uma certa relevância sobre o aspecto socioeconômico, perante a enorme carência de outras fontes promissoras de trabalho e renda. No entanto, o desperdiço exorbitante desse recurso mineral durante o processo de beneficiamento pode ser considerado um fator que possa prejudicar o desenvolvimento e a continuidade dessa atividade futuramente, em decorrência do esgotamento das jazidas. Além disso, a mineração realizada de forma não planejada compromete a qualidade da água e do solo deixando o local inoperante para realização de outras atividades como agricultura e a pecuária.

Dada a relevância dos impactos negativos que a atividade de exploração do calcário laminado tem proporcionados ao município santanense, principalmente no que tange a geração excessiva do rejeito de calcário resultante do processo de lavra, torna-se necessária uma atuação imediata dos órgãos públicos 
municipais, estaduais, federais e das próprias empresas na formulação de ações que possam minimizar ou até neutralizar os efeitos degradantes de tais impactos. Além disso, faz-se necessária também o comprometimento da população na resolução dessa problemática, em relação a questões associadas a consciência ambiental.

\section{REFERÊNCIAS}

BÁEZ, A. M.; MOURA, G. J. B.; GÓMEZ, R. O.. Anurans from the Lower Cretaceous Crato Formation of northeastem Brazil: implications of the early divergence of neobatrachians. Crataceous Research, v.30, p.829-846, 2009.

BARDOLA, T. P.. Caracterização paleoambiental dos carbonatos microbiais do Membro Crato, Formação Santana, aptiano-albiano da bacia do Araripe. Dissertação (Mestrado em Geociências) - Universidade Federal do Rio Grande do Sul, Porto Alegre, 2015.

BEZERRA, L. M. A.. Análise dos impactos socioambientais decorrentes da mineração na chapada do Araripe-Nova, Olinda (CE). Geosaberes, v.6, n.2, p.79-89, 2015.

BIZAWU, K.; MOREIRA, R. L.. Licenciamento ambiental e a Política Nacional de Segurança de Barragem: Lei 12.334/2010. Revista Jurídica, v.3, n.48, p.271-298, 2017.

CASELLI, F. T. R.; GOMES, M. L. B. G.. Formação de Arranjo Produtivo Local (APL) Como Promotor da Competitividade de Micro e Pequenas Empresas - MPEs: Analise no APL Mineral - CE. Revista Espacios, v.36, n.17, p.5, 2015.

CPRM. Companhia de Pesquisa de Recursos Minerais. Programa de recenseamento de fontes de abastecimento por água subterrânea no estado do Ceará: diagnóstico do município de Santana do Cariri. Fortaleza: CPRM, 1998.

CRESWELL, J.. Procedimentos de métodos mistos. In: Projeto de pesquisa: métodos qualitativo e quantitativo e misto. 3 ed. Porto Alegre: PSO, 2010.

DNPM. Departamento Nacional de Produção Mineral. Anuário mineral estadual: Ceará: anos base 2014 e 2015. Brasília: DNPM, 2016.

DNPM. Departamento Nacional de Produção Mineral. Normas Reguladoras de Mineração: NRM. Brasília: DNPM, 2001.

DURÃES, M. C. O.. Caracterização dos impactos ambientais da mineração na bacia hidrográfica do Rio São Lamberto, Montes Claros (MG). Caderno de Ciências Agrárias, v.9, n.1, p.49-61, 2017.

IBGE. Instituto Brasileiro de Geografia e Estatística. Panorama do município de Santana do Cariri. Rio de Janeiro: IBGE, 2010.

IPECE. Instituto de Pesquisa e Estratégia Econômica do Ceará. Perfil Básico Municipal 2016: Santana do Cariri. Fortaleza: IPECE, 2016.

MENDONÇA, L. A. R.. Problemas de cálcio na água de abastecimento de Nova Olinda (CE). Engenharia Sanitária e Ambiental, v.13, n.3, p.298-305, 2008.

MOURA, R. D.; SOUZA, D. N. C.; LUIZ, D. M. R. L.. Classificação do calcário da região do Cariri oriental paraibano usado na produção de carbonato de cálcio. In: CONGRESSO BRASILEIRO DE ENGENHARIA QUÍMICA, 20. Anais. São Luís: ABQ, 2014.

NEUMANN, V. H. M. L.; CABRERA, L.. Características hidrogeológicas gerais, mudanças de salinidade e caráter endorréico do Sistema Lacustre Cretáceo do Araripe. Revista de Geologia, v.15, p.43-54, 2002.

NOVAES, R. L. M.; LAURINDO, R. D. S.. Morcegos da Chapada do Araripe, Nordeste do Brasil. Papéis Avulsos de Zoologia, v.54, n.22, p.315-328, 2014.

OLIVEIRA FILHO, G. R.. Uma breve reflexão sobre o conceito de impacto ambiental. CES Revista, v.27, n.1, p.15-28, 2013.

SÁNCHEZ, L. E.. Avaliação de impacto ambiental: conceitos e métodos. 2 ed. São Paulo: Oficina de Textos: 2013.

SANTOS, E. G.. Recuperação ambiental na disposição de estéril em mineração de calcário. Revista Monografias Ambientais, v.14, p.14-32, 2015.

SILVA, A. D. A.. Aproveitamento de rejeito de calcário do Cariri cearense na formulação de argamassa. In: CONGRESSO BRASILEIRO DE ROCHAS ORNAMENTAIS E VI SIMPÓSIO DE ROCHAS ORNAMENTAIS DO NORDESTE, 3. Anais. Rio de Janeiro, 2007.

A CBPC - Companhia Brasileira de Produção Científica (CNPJ: 11.221.422/0001-03) detém os direitos materiais desta publicação. Os direitos referem-se à publicação do trabalho em qualquer parte do mundo, incluindo os direitos às renovações, expansões e disseminações da contribuição, bem como outros direitos subsidiários. Todos os trabalhos publicados eletronicamente poderão posteriormente ser publicados em coletâneas impressas sob coordenação da Sustenere Publishing, da Companhia Brasileira de Produção Científica e seus parceiros autorizados. Os (as) autores (as) preservam os direitos autorais, mas não têm permissão para a publicação da contribuição em outro meio, impresso ou digital, em português ou em tradução. 